\title{
Suppressive Actions of Astragali Radix (AR) Ethanol Extract and Isolated Astragaloside I on HCl/ethanol-Induced Gastric Lesions
}

\author{
Jeong Suk Jeong ${ }^{1}$, Je-Hyuk LeE ${ }^{2}$, Sang Hyup Lee ${ }^{1}$, Sam Sik Kang ${ }^{3}$, and Choon Sik Jeong ${ }^{1, *}$ \\ ${ }^{1}$ College of Pharmacy, ${ }^{2}$ Plant Resources Research Institute, Duksung Women's University, Seoul 132-714, \\ ${ }^{3}$ College of Pharmacy, Seoul National University, Seoul 151-742, Republic of Korea
}

(Received November 30, 2008; Revised December 26, 2008; Accepted December 26, 2008)

\begin{abstract}
Roots of Astragalus membranaceus (A. membranaceus) (Astragali Radix, AR) has been used as a herbal medicine for gastrointestinal disorders in China, Korea, Japan, and other Asia countries. In this study we investigated the effects of the AR $70 \%$ ethanol extract and compounds isolated from AR on gastritis in rats and growth of human gastric cancer cells. AR 70\% ethanol extract showed the potent acid-neutralizing capacities and partly cytotoxicity of Helicobacter pylori and human AGS gastric cancers cell. Astragaloside I and daucosterol, which were isolated from AR, significantly inhibited $\mathrm{HCl} / \mathrm{ethanol-induced} \mathrm{gastric} \mathrm{lesions.} \mathrm{In}$ addition, daucosterol increased the mucus content to almost the same as the positive control. The results of this study suggest that astragaloside I and daucosterol may be good candidates for the development of new drugs or neutraceuticals which can be used for the treatment or prevention of gastritis.
\end{abstract}

Keywords: Astragalus membranaceus, Astragali Radix (AR), Astragaloside I, Gastritis, Helicobacter pylori

\section{INTRODUCTION}

Recently it has been recognized that the infection of the gastric mucosa with $H$. pylori usually causes both an acute and chronic inflammation cell infiltrate, leading to an increase of reactive oxygen species (ROS), which are highly reactive compounds capable of combining with DNA in a number of potentially genotoxic ways, and are accumulated in H. pylori gastritis (Drake et al., 1998). The gastrointestinal lesions, such as gastric ulcers, and gastric cancers are strongly associated with $H$. pylori infection. One way in which it may be possible to prevent carcinogenesis would be to reduce ROS damage to cellular constituents, especially DNA. In addition, the pathological condition of the recurring gastritis and gastric ulcers causes an imbalance between aggressive factors (i.e., gastric acid, pepsin, and secretion of gastrin) and protective factors (i.e., mucus productivity, mucus secretion, and prostaglandins) (Shay et al., 1945). Physiological factors of these gastric diseases include acid-pepsin secretion, parietal cell activity, mucosal barrier, mucus secretion, blood flow, cell regeneration, and the release of endogeneous protective

*Corresponding author

Tel: +82-2-901-8382 Fax: +82-2-901-8386

E-mail: choonsik@duksung.ac.kr agents, especially prostaglandins and epidermal growth factors (Gyires, 2005).

The genus Astragalus includes approximately 2,000 species and is distributed mainly in the northern temperate regions and tropical African mountains (Evans, 2002); five species of this genera have been identified in Korea (Lee, 1989). Astragali Radix (AR), the dry root of Astragalus membranaceus (A. membranaceus) (Fisch.) Bge. (Leguminosae), has been used as one of the most important tonic herbs in traditional medicine. Pharmacological studies of AR have demonstrated that AR possesses many biological functions, including hepatoprotective (Ríos et al., 1997; Gui et al., 2006), neuroprotective effect against ischemic brain injury (Luo et al., 2004; Tohda et al., 2006), immunological properties (Shao et al., 2004; Li et al., 2007; Cho et al., 2007a), cardiotonic (Zhang et al., 2006a; Zhang et al., 2006b), antiaging activities (Lei et al., 2003), gastroprotective (Navarrete et al., 2005), adjuvant (Rajput et al., 2007), antitumor effects (Cho et al., 2007b; Tin et al., 2007), anti-inflammatory (Zhang et al., 2003), and the growth of new tissues (Cheng et al., 2006; Choi et al., 2007).

The present work was carried out to investigate the potential anti-ulcerogenic and anti-gastric effects of AR extract and its several constituents. This result suggests that 
AR may be a good candidate for the development of new drugs or neutraceuticals which can be used for the treatment or prevention of gastritis.

\section{MATERIALS AND METHODS}

\section{Materials}

Three years-old roots of $A$. membranaceus were harvested at Jungsun, Kangwon, Korea in September, 2004. The plant and root were identified by Prof. S. Kang. (College of Pharmacy, Seoul National University). The voucher specimen (SNU-594) was deposited at the herbarium of the College of Pharmacy, Seoul National University, Seoul, Korea.

Fetal bovine serum (FBS), RPMI Medium 1640, and Hank's balanced salt solution were obtained from GIBCO Co. (Grand Island, NY). Dantrolene sodium, 3-(4,5-dimethylthiazol-2-yl)-2,5-diphenyl tetrazolium bromide (MTT), 1,1-diphenyl-2-picrylhydrazyl radical (DPPH), trypan blue, probenecid, dimethyl sulfoxide (DMSO), sodium bicarbonate, penicillin-streptomycin, trypsin-EDTA, cimetidine, and ampicillin were obtained from Sigma Chemical Co. (St. Louis, MO). $\mathrm{HCl}$, ethanol, and other solvents were purchased from Duksan Pure Chemical Co. Ltd. (Kyunggi-do, Korea). Silica gel 60, Kieselgel 60, Kieselgel 77, and TLC plate were from MERCK, Ltd. (Darmstadt, Germany). All other reagents and solvents were the pharmaceutical or analytical grade.

\section{Animals}

Male Sprague-Dawley rats weighing $180-200 \mathrm{~g}$ were purchased from Samyook Animal Laboratories, Kyunggido, Korea, and were acclimatized to standard laboratory conditions $\left(24 \pm 2^{\circ} \mathrm{C}, 55 \pm 5 \%\right.$ humidity and $12 \mathrm{~h}$ light/dark cycle) for 14 days in the animal facility in Duksung Women's University. The samples dissolved in saline were administered in a volume of $0.5 \mathrm{ml}$ per $100 \mathrm{~g}$ (body weight). The control group was given saline only. The experimental procedures for Sprague-Dawley rats were conducted in accordance with the Guidelines of the Care and Use of Laboratory Animals, Duksung Women's University. The animals were allowed free access to food (standard pellet diet) and water ad libitum. All this study was carried out in compliance with the Testing Guidelines for Safety Evaluation of Drugs (Notification No. 1999-61) issued by the Korea Food and Drug Administration, the Good Laboratory Practice Regulations for Non-clinical Laboratory Studies (Notification No. 2000-63) issued by the Korea Food and Drug Administration, and the Principles of Good Laboratory Practice issued by the Organization for Econo- mic Cooperation and Development.

\section{Preparing extract and isolation constituents from AR}

AR $(17.8 \mathrm{~kg})$ was chopped into small pieces and refluxed with $70 \%$ ethanol for $3 \mathrm{~h}$ at $70-80^{\circ} \mathrm{C}$. The $70 \%$ ethanol extract was evaporated under reduced pressure and then fractionated successively with water and hexane (137 $\mathrm{g})$, ethyl acetate $(145 \mathrm{~g})$, and then butanol $(340 \mathrm{~g})$. The ethyl acetate ( $143.8 \mathrm{~g}$ ) was separated by column chromatography (CC) over silica gel with dichloromethane/ methanol (gradient) to yield 51 subfractions (Fr. E-01-Fr. E-51). Fr. E-45 (20 g) was further purified on a silica gel column (ethyl acetate/methanol/water; 100:1:0.5 $\rightarrow 100: 2: 1$ ) to yield 70 subfractions (Fr. E-45-01 - Fr. E-45-70). Subfraction E-45-50 (4.5 g) were chromatographed on an RP-18 column with $80 \%$ methanol to afford E-45-50-8 $(3.2 \mathrm{~g})$ and repeated silica gel CC (chloroform/methanol/water; 7:0.5: 0.5 ) to afford astragaloside I (1.61 g, Fig. 1) from E-4550-8-25. Subfraction E-23 (1 g) was purified on an RP-18 column with hexane-ethyl acetate (gradient) to yield subfraction E-23-221, which was crystallized from dichloromethane/ methanol to yield formononetin (150 mg, Fig. 1). The butanol soluble fraction was fractionated by $\mathrm{CC}$ over silica gel (dichloromethane/methanol/water; 7:1:0.5 $\rightarrow$ 7:2:0.5 - 7:3:1) to yield 39 fractions (Fr. B-01 - Fr. B-39). Fr. B-20 $(1.5 \mathrm{~g})$ was rechromatographed on an RP-18 column with $80 \%$ methanol to afford astragaloside IV $(250 \mathrm{mg}$, Fig. 1) from subfraction $B-20-23$. The compounds were identified as daucosterol, formononetin, astragaloside I, and astragaloside IV by NMR and LC/MS and comparison with literature data (Hirotani et al., 1994; Kim et al., 1996; Lee et al., 2007).

\section{Acid-neutralizing capacity}

One gram of extracts and constituents was added to $100 \mathrm{ml}$ of $0.1 \mathrm{~N} \mathrm{HCl}$ and then incubated for $1 \mathrm{~h}$ at $37^{\circ} \mathrm{C}$ with a shaking. Acid-neutralizing capacity was determined by titrating with $0.1 \mathrm{~N} \mathrm{NaOH}$ using methyl orange as an indicator. Hydrotalcite and cimetidine were used as a positive control.

\section{Determination of antioxidant activity}

One milliliter of DPPH $(150 \mu \mathrm{M})$ was added to $4 \mathrm{ml}$ of extracts/constituents $(2.5-120 \mu \mathrm{g} / \mathrm{ml})$, and then the mixture was stirred. After $30 \mathrm{~min}$ incubation at room temperature, the absorbance of the samples was read against a blank on $520 \mathrm{~nm}$. Scavenging the DPPH free radical in percent (Inhibition \%, I\%) was calculated as followings;

$$
I \%=\left(A_{\text {blank }}-A_{\text {sample }} / A_{\text {blank }}\right) \times 100
$$

$A_{b l a n k}$ is the absorbance of the mixture without samples 


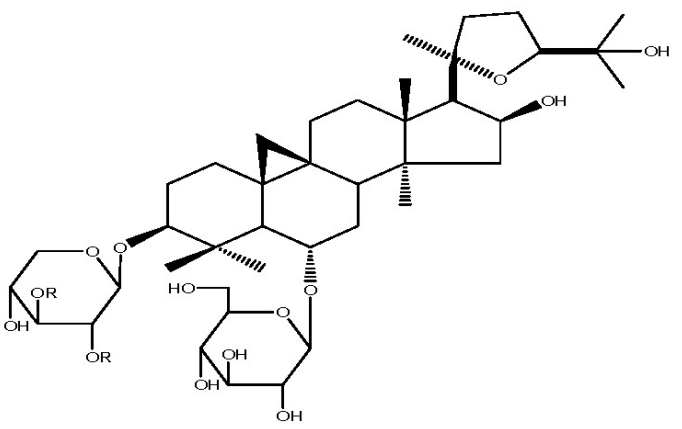

Astragaloside I $\quad \mathrm{R}=\mathrm{AC}$

Astragaloside IV $\quad \mathrm{R}=\mathrm{H}$

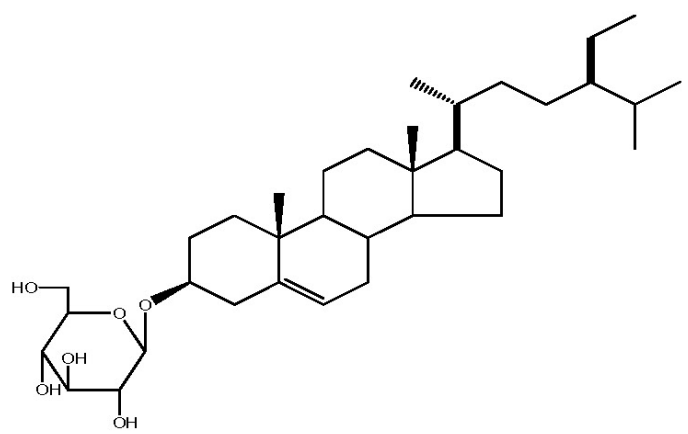

Daucosterol

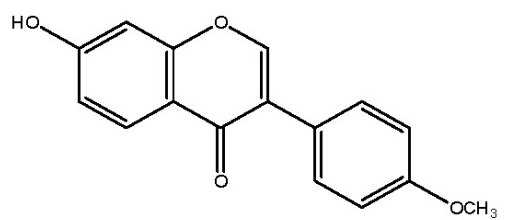

Formononetin

Fig. 1. Chemical structure of astragaloside I, astragaloside IV, daucosterol, and formononetin.

and $A_{\text {sample }}$ is the absorbance of the mixture with samples. Concentration providing $50 \%$ inhibition $\left(\mathrm{IC}_{50}\right)$ was determined from the graph plotted inhibition percentage against concentration. L-Ascorbic acid was used as a positive control (Tepe and Sokmen, 2007).

\section{Anti-H. pylori activity}

$H$. pylori strain was obtained from American Type Culture Collection (ATCC, Rockville, MD). The inhibitory effect of AR ethanol extract and its constituents on the growth of $H$. pylori was investigated. Six hundred microliter of samples was mixed to $5.4 \mathrm{ml}$ of brucella agar medium containing $7 \%$ horse serum in the petri dish. $H$. pylori $\left(5 \times 10^{5} \mathrm{CFU}\right)$ was seeded in this media and then incubated for 3 days at $37^{\circ} \mathrm{C}$ incubator (AnaeroPak Campylo: $85 \%$ $\mathrm{N}_{2}, 10 \% \mathrm{CO}_{2}, 5 \% \mathrm{O}_{2}$ ). Ampicillin was used as a positive control (Kim et al., 2003).

\section{Cell culture}

Human gastric cancer cell lines, AGS and SNU638, were obtained from Korean Cell Line Bank (KCLB, Seoul, Korea). Gastric cancer cells were grown at $37^{\circ} \mathrm{C}$ in a $5 \%$ $\mathrm{CO}_{2}$ humidified incubator in a MEM containing $10 \% \mathrm{FBS}$, $200,000 \mathrm{IU} / \mathrm{L}$ penicillin, $200 \mathrm{mg} / \mathrm{L}$ of streptomycin, and 1 $\mathrm{mM}$ sodium pyruvate. After reaching confluence, the cells were subcultured by trypsinization. SNU and AGS cells were rinsed twice with phosphate buffered saline (PBS, pH 7.4) to remove all traces of serum (which can inhibit trypsin) and were subdivided using $0.05 \%$ trypsin with 0.53 mM EDTA.

\section{Cytotoxicity assay}

Cell viability was assessed by the MTT method (van de Loosdrecht et al., 1991). Cells were seeded in 24-well plates at the density of $5 \times 10^{4}$ cells/well. After $24 \mathrm{~h}$ incubation with samples, $100 \mu \mathrm{l}$ of MTT ( $5 \mu \mathrm{g} / \mathrm{L}$ in water) were added to every well and the plates were incubated for a further $4 \mathrm{~h}$. Two hundred microliter of DMSO was added to every well and mixed by pipetting to dissolve the MTT formazans completely. Relative cell viability was obtained by measuring the absorbance by an ELISA reader (Molecular Devices, Menlo Park, CA) on $540 \mathrm{~nm}$.

\section{$\mathrm{HCl} /$ ethanol-induced gastric lesion}

The rats, which were fasted for $24 \mathrm{~h}$ with free access to water prior to the experiment, were orally administered with AR 70\% ethanol extract or its constituents (Mizui and Dodeuchi, 1983). After $30 \mathrm{~min}, 0.5 \mathrm{ml} / 100 \mathrm{~g}$ of a HCl/ethanol $(150 \mathrm{mM} \mathrm{HCl}$ in $60 \%$ ethanol) solution was given orally for the induction of gastric lesions. One hour later, the animals were anesthetized with ether, and their stomachs were removed and fixed with $2 \%$ formalin for $10 \mathrm{~min}$. The amount of hemorrhage on the glandular portion was measured by summing the total length $(\mathrm{mm})$ of each lesion and expressed as a lesion index.

\section{Gastric secretion}

The rats were immediately administered daucosterol and Astragaloside I isolated from AR or cimetidine intraduodenally after the pyloric ligation (Shay et al., 1945). Four hours after the pyloric ligation, the animals were sacrificed, and the contents of the stomach were collected and centrifuged at $1,050 \times \mathrm{g}$ for $10 \mathrm{~min}$. The total volume of gastric juice and $\mathrm{pH}$ were measured, and an acid output $(\mathrm{mEq} / \mathrm{ml})$ was determined by titrating the gastric juice with $0.05 \mathrm{~N} \mathrm{NaOH}$ using phenolphthalein as an indicator. 


\section{Mucus secretion}

The constituents from AR were administrated orally to the rats. After $30 \mathrm{~min}$, an absolute ethanol $(1 \mathrm{ml} / 100 \mathrm{~g})$ was given orally to induce the gastric lesions. One hour later, the animals were sacrificed and the secreted mucus was determined (Kitagawa et al., 1986). The glandular portion separated from the excised stomach was opened along the lesser curvature and everted. The stomach was soaked in $0.1 \%$ alcian blue $8 \mathrm{GX}$ dissolved in $0.16 \mathrm{M}$ sucrose buffered with $0.05 \mathrm{M} \mathrm{CH}_{3} \mathrm{COONa}$ (adjusted to $\mathrm{pH}$ 5.8 with $\mathrm{HCl}$ ) for $2 \mathrm{~h}$. The mucus combined with the alcian blue was extracted with $20 \mathrm{ml}$ of $70 \%$ ethanol containing $30 \%$ dioctyl sodium sulfosuccinate and centrifuged for 10 $\min$ at $500 \times \mathrm{g}$. The optical density of the supernatant was measured at $620 \mathrm{~nm}$ using by UV-spectrophotometer (Agilent Technologies Inc., Santa Clara, CA, USA).

\section{Statistical analysis}

All experiments were performed four times. Data were expressed as mean \pm standard error of the mean (SEM), and were analyzed using one way analysis of variance (ANOVA) and Student-Newman-Keul's test for individual comparisons. $p$-values less than 0.05 are considered statistically significant.

\section{RESULTS AND DISCUSSION}

\section{Acid-neutralizing capacity}

AR $70 \%$ ethanol extract inhibited approximately $38.80 \%$ of $\mathrm{NaOH}$-consumption volume, which was better than that of cimetidine as a positive control (Table I). $\mathrm{NaOH}$-consumption volume by astragaloside IV, daucosterol, and formononetin, which were isolated from AR, was decreased to $5.01,6.15$, and $2.01 \%$, respectively. However,

Table I. Acid-neutralizing capacity of AR $70 \%$ ethanol extract and its constituents

\begin{tabular}{lcc}
\hline Material & $\begin{array}{c}\text { NaOH consumption } \\
\text { volume (\% control) }\end{array}$ & Inhibition (\%) \\
\hline Control & $99.33 \pm 1.15$ & - \\
AR 70\% ethanol extract & $60.08 \pm 5.36^{*}$ & 38.80 \\
Astragaloside I & $101.94 \pm 4.11$ & -1.94 \\
Astragaloside IV & $94.35 \pm 3.04^{*}$ & 5.01 \\
Daucosterol & $93.85 \pm 5.11^{*}$ & 6.15 \\
Formononetin & $97.33 \pm 2.52$ & 2.01 \\
Hydrotalcite & $31.66 \pm 5.77^{* *}$ & 68 \\
Cimetidine & $87.06 \pm 5.65^{\star}$ & 12.94 \\
\hline
\end{tabular}

The values are mean \pm SEM. Significant difference, ${ }^{*} p<0.05,{ }^{* *} p$ $<0.01$, as compared to the control. astragaloside I did not show the acid-neutralizing activity. Acid-neutralizing capacity of AR $70 \%$ ethanol extract, which is extra-ordinarily superior among the natural extract materials, may be expected to exert the protective influence on stomach damage by secretion of gastric acid, when taken in a long period.

\section{Antioxidant activity}

The antioxidant property plays an important role for the inhibition of oxidation processes, which are involved in the mechanisms of several gastric disorders, including ulceration (La Casa et al., 2000). IC $\mathrm{C}_{50}$ of L-ascorbic acid as positive control was $<5 \mu \mathrm{g} / \mathrm{ml}$. However, AR ethanol extract and its any constituents did not show the effective scavenging activity against DPPH free radicals (Table II), in spite of its potent acid-neutralizing capacity.

It has been widely accepted that a large number of free radicals is generated in the peptic ulcer and gastritis. In addition, the involvement of oxygen derived free radicals are well established in the pathogenesis of ischaemic injury of gastrointestinal mucosa and in other models of mucosal damage induced by non-steroidal anti-inflammatory drugs, ethanol, and $H$. pylori (Drake et al., 1998). The radicals also promote mucosal damage by causing degradation of the epithelial basement membrane components, complete alteration of the cell metabolism, and DNA damage. From this report, it is likely to speculate that AR ethanol extract and its constituents have low antioxidant action to play a role to anti-ulcer and gastritis.

\section{Anti-H. pylori activity}

$H$. pylori is the major cause for bacterial gastrointestinal infections in adults and children. Also, it is believed to be a cause of peptic ulcer (Gerrits et al., 2006) and gastric cancer (Matysiak-Budnik and Megraud, 2006). Antibiotic therapy using the combination of two or three drugs has been widely used to eradicate these infections. However, the development of drug-resistance in bacteria needs novel sources of drugs, and therefore plants seem to be a desirable source of new antibacterial compounds. Indeed, the

Table II. DPPH-radical scavenging activity of AR 70\% ethanol extract and its constituents

\begin{tabular}{lc}
\hline Material & $\mathrm{IC}_{50}(\mu \mathrm{g} / \mathrm{ml})$ \\
\hline AR 70\% ethanol extract & $>160$ \\
Astragaloside I & $>160$ \\
Astragaloside IV & $>160$ \\
Daucosterol & $>160$ \\
L -Ascorbic acid & $<5$ \\
\hline
\end{tabular}


medicinal plants and/or their chemical components have been reported to have a potential benefit in eradicating such problems (Nostro et al., 2005). Recently the phenolic phytochemicals, such as cinnamic acids, cinnamaldehydes, coumarins phenolic acids, capsaicin, flavonoids, and tannins from peppers, wine, and many other natural products, showed the high anti-H. pylori activity (Bae et al., 1999). This result shows that AR $70 \%$ ethanol extract and astragaloside I inhibited partly the colonization of $H$. pylori at 50 and $100 \mu \mathrm{g} / \mathrm{ml}$ of concentration (Table III).

\section{Cytotoxicity}

Cytotoxicity was assessed by measuring cell viability of human gastric cancer cells, AGS and SNU-638. AR 70\% ethanol extract showed a significant cytotoxicity against AGS gastric cancer cell line (IC $\mathrm{C}_{50}=165.76 \mu \mathrm{g} / \mathrm{ml}$ ) (Table IV). AR $70 \%$ ethanol extract and its several constituents did not show cytotoxicity against SNU638 gastric cancer cell line.

For the prevention of gastric cancer disease, it is very important to develop the natural herbal medicine to act to the cancer cells directly as well as to associated risk factors, such as $H$. pylori infection and a maintaining ascorbic acid. Recently, the development of new anticancer drug is a key issue for cancer chemotherapy because of the reality that cancer cells, which are resistant to chemotherapy, will eventually cause mortality. Herbal medicines as sub-

Table III. Inhibitory effect of AR $70 \%$ ethanol extract and its constituents on the colonization of $H$. pylori

\begin{tabular}{|c|c|c|}
\hline Material & Dose $(\mu \mathrm{g} / \mathrm{ml})$ & Colonization \\
\hline Control & & $+++^{\mathrm{a}}$ \\
\hline \multirow[t]{3}{*}{ AR $70 \%$ ethanol extract } & 10 & +++ \\
\hline & 50 & $++^{\mathrm{b}}$ \\
\hline & 100 & ++ \\
\hline \multirow[t]{3}{*}{ Astragaloside I } & 10 & +++ \\
\hline & 50 & ++ \\
\hline & 100 & $+^{c}$ \\
\hline \multirow[t]{3}{*}{ Astragaloside IV } & 10 & +++ \\
\hline & 50 & +++ \\
\hline & 100 & +++ \\
\hline \multirow[t]{3}{*}{ Daucosterol } & 10 & +++ \\
\hline & 50 & +++ \\
\hline & 100 & +++ \\
\hline \multirow[t]{3}{*}{ Formononetin } & 10 & +++ \\
\hline & 50 & +++ \\
\hline & 100 & +++ \\
\hline Ampicillin & 100 & $-{ }^{d}$ \\
\hline
\end{tabular}

stitutes for cancer remedies have attracted a great deal of interest, because of their low toxicity and costs. However taken together, it is expected that AR ethanol extract and its constituents have low cytotoxic actions on human gastric cancer cells.

\section{The effects of AR-constituents on $\mathrm{HCl} /$ ethanol-induced gastric lesion}

The $\mathrm{HCl} /$ ethanol-induced gastric lesions are caused by the direct irritation to a gastric mucosal barrier (Seiki et al., 1990). The mechanism of ethanol-induced gastric lesions varies, including the depletion of gastric mucus content, damaged mucosal blood flow, and mucosal cell injury. In addition, ethanol-induced gastric mucosal damage is associated with overproduction of free radicals, which lead to an increased lipid peroxidation (Kahraman et al., 2003). Ethanol induces both long ulcers and petechial lesions within a relatively short time, which makes this technique suitable for screening methods for investigation of anti-ulcer drugs. The effects of AR-constituents on the $\mathrm{HCl} /$ ethanol-induced lesion were summarized in Table $\mathrm{V}$. Lesion index of control group was $66.7 \pm 6.77 \mathrm{~mm}$. Astragaloside I $(100 \mathrm{mg} / \mathrm{kg})$ and daucosterol $(50 \mathrm{mg} / \mathrm{kg})$ significantly decreased approximately 51.1 and $42.6 \%$ of lesion index, re-

Table IV. Cytotoxicity of AR $70 \%$ ethanol extract and its constituents against SNU638 and AGS cells

\begin{tabular}{|c|c|c|}
\hline \multirow{2}{*}{ Material } & SNU638 & AGS \\
\hline & \multicolumn{2}{|c|}{$\mathrm{IC}_{50}(\mu \mathrm{g} / \mathrm{ml})$} \\
\hline AR $70 \%$ ethanol extract & $>200$ & 165.76 \\
\hline Astragaloside I & $>200$ & $>200$ \\
\hline Astragaloside IV & $>200$ & $>200$ \\
\hline Daucosterol & $>200$ & $>200$ \\
\hline
\end{tabular}

Table V. Effects of AR-constituents on $\mathrm{HCl} /$ ethanol-induced gastric lesion

\begin{tabular}{lccc}
\hline Material & Dose $(\mathrm{mg} / \mathrm{kg})$ & Lesion index $(\mathrm{mm})$ & Inhibition $(\%)$ \\
\hline Control & - & $66.7 \pm 6.77$ & - \\
Astragaloside I & 50 & $51.2 \pm 1.65$ & 22.07 \\
& 100 & $32.1 \pm 0.99^{\star *}$ & 51.1 \\
Daucosterol & 50 & $37.7 \pm 0.79^{\star *}$ & 42.6 \\
& 100 & $65.3 \pm 0.39$ & 0.6 \\
Formononetin & 50 & $60.7 \pm 0.99$ & 7.61 \\
& 100 & $40.8 \pm 0.53^{*}$ & 37.9 \\
Sucralfate & 375 & $26.5 \pm 0.10^{\star *}$ & 59.7 \\
Cimetidine & 100 & $45.7 \pm 0.30$ & 30.4 \\
Hydrotalcite & 100 & $36.8 \pm 0.28^{\star *}$ & \\
\hline
\end{tabular}

The values are mean \pm SEM of 6 animals. ${ }^{*} p<0.01,{ }^{* *} p<0.001$, as compared to the control. 
spectively, which were better than or equivalent to that of cimetidine $(100 \mathrm{mg} / \mathrm{kg})$, sucralfate $(375 \mathrm{mg} / \mathrm{kg})$, and hydrotalcite $(100 \mathrm{mg} / \mathrm{kg})$, as positive controls. In case of daucosterol, the inhibitory effect against $\mathrm{HCl} /$ ethanol-induced gastric lesions was not concentration-dependency. Based on cytotoxicity of many flavonoids and saponins at high dose to the tissues, its reason is likely to cytotoxicity of high dose-daucosterol. Furthermore, the new drug, effective at low dose, is critical for anti-gastritis treatment. Therefore, the study for lower dose of daucosterol will be performed in the future. Except the potent acid-neutralizing activity, AR $70 \%$ ethanol extract and its constituents did not show the effective free radical quenching activity and cytotoxicity on $H$. pylori and human cancer cell lines in vitro. However, in vivo astragaloside $\mathrm{I}$, which is one of the major components in AR, exerted the significant inhibition on $\mathrm{HCl} /$ ethanol-induced lesion, and this anti-gastric activity could be explained by the acid-neutralizing capacity of AR.

\section{The effects of astragaloside I and daucosterol on gastric secretion}

The effects of astragaloside I and daucosterol, which were constituents of $\mathrm{AR}$, on gastric secretion, $\mathrm{pH}$, and acid output in pylorus-ligated rats were examined in Table VI. We measured the gastric-juice parameters, such as gastric volume and $\mathrm{pH}$, after submitting the rats to pylorus liga-

Table VI. Effect of astragaloside I and daucosterol on gastric secretion in pylorus-ligated rats

\begin{tabular}{lcccc}
\hline Material & $\begin{array}{c}\text { Dose } \\
(\mathrm{mg} / \mathrm{kg})\end{array}$ & $\begin{array}{c}\text { Volume } \\
(\mathrm{ml})\end{array}$ & $\mathrm{pH}$ & $\begin{array}{c}\text { Total acid output } \\
(\mathrm{mEq} / 4 \mathrm{~h})\end{array}$ \\
\hline Control & - & $5.4 \pm 2.53$ & $0.7 \pm 0.04$ & $0.47 \pm 0.02$ \\
Astragaloside $\mathrm{I}$ & 100 & $5.7 \pm 1.79$ & $1.3 \pm 0.04$ & $0.41 \pm 0.01$ \\
Daucosterol & 50 & $7.2 \pm 2.40$ & $1.4 \pm 0.04$ & $0.42 \pm 0.02$ \\
Cimetidine & 100 & $2.8 \pm 1.35^{\star}$ & $2.7 \pm 0.02^{* *}$ & $0.09 \pm 0.01^{* *}$ \\
\hline
\end{tabular}

Total gastric juice volume and $\mathrm{pH}$ were measured $4 \mathrm{~h}$ after the pyloric ligation. The values are mean \pm SEM of 6 animals. ${ }^{*} p<0.01$, ${ }^{\star *} p<0.001$, as compared to the control.

Table VII. Effects of astragaloside I and daucosterol on mucus contents from ethanol-induced gastric lesion in rats

\begin{tabular}{lcc}
\hline Material & $\begin{array}{c}\text { Dose } \\
(\mathrm{mg} / \mathrm{kg})\end{array}$ & $\begin{array}{c}\text { Mucus content } \\
(\mu \mathrm{g} \text { as alcian blue })\end{array}$ \\
\hline Control & - & $122.8 \pm 7.91$ \\
Astragaloside I & 100 & $120.2 \pm 7.36$ \\
Daucosterol & 50 & $162.9 \pm 6.86^{*}$ \\
Sucrafate & 375 & $125.6 \pm 8.23$ \\
\hline
\end{tabular}

The values are mean \pm SEM of 6 animals. ${ }^{*} p<0.01$, as compared to the control. ture with or without the astragaloside I and daucosterol intraduodenally. Doses of astragaloside I and daucosterol were selected based on suppression of $\mathrm{HCl}$-ethanol-induced gastric lesion (Table V). Cimetidine was used for a positive control. Astragaloside I $(100 \mathrm{mg} / \mathrm{kg})$ and daucosterol $(50 \mathrm{mg} / \mathrm{kg})$ showed no significant change in gastric volume and acid output, but increased the gastric $\mathrm{pH}$ significantly. Despite of no change in gastric volume and acid output, the increase of gastric $\mathrm{pH}$ is presumed to play important role to anti-gastric effect, including the reduction of lesion index in vivo.

\section{The effects of astragaloside I and daucosterol on mucus secretion}

Daucosterol $(50 \mathrm{mg} / \mathrm{kg})$ significantly increased the mucus content to $162.9 \pm 6.86 \mu \mathrm{g}$, which was better than that of sucralfate as a positive control (Table VII). In the mucus secretion model, even though ethanol induces to reduce the amount of mucus secretion in the rats, daucosterol enhanced the mucus secretion. The amount of mucus secretion by sucralfate was similar to control group. The reason might be by a protective action for stomach damage through sucralfate-coating than by the increase of mucus secretion in response to ethanol irritation. Therefore, the gastro-protective activity of daucosterol was expected to be caused by the stimulation of mucus secretion.

In present study, AR ethanol extract showed the potent acid-neutralizing capacities, the partial inhibition of $H$. pylori and AGS human gastric cancer cell line. Astragaloside I and daucosterol, which were isolated from AR, exhibited protective effect against ethanol-induced gastric mucosal lesion through one or more possible mechanisms including stimulation of mucus secretion. Therefore, AR ethanol extract, Astragaloside I, and daucosterol are expected to have potential protective effect against gastritis.

\section{ACKNOWLEDGMENTS}

This study was supported by a grant from the Food \& Drug Administration, Republic of Korea and the Korea Research Foundation Grant funded by the Korean Government (MOEHRD)(KRF-2008-005-J00601).

\section{REFERENCES}

Bae, E. A., Han M. J. and Kim, D. H. (1999). In vitro antiHelicobacter pylori activity of some flavonoids and their metabolites. Planta. Med. 65, 442-443.

Cheng, C. Y., Yao, C. H., Liu, B. S., Liu, C. J., Chen, G. W. and Chen, Y.S. (2006). The role of astragaloside in regeneration of the peripheral nerve system. J. Biomed. Mater. Res. 76, 
463-469.

Cho, W. C. S. and Leung, K. N. (2007a). In vitro and in vivo anti-tumor effects of Astragalus membranaceus. Cancer. Lett. 252, 43-54.

Cho, W. C. S. and Leung, K. N. (2007b). In vitro and in vivo immunomodulating and immunorestorative effects of Astragalus membranaceus. J. Ethnopharmacol. 113, 132141.

Choi, S. I., Heo, T. R., Min, B. H., Cui, J. H., Choi, B. H. and Park, S. R. (2007). Alleviation of osteoarthritis by calycosin7-O-beta-D-glucopyranoside (CG) isolated from Astragali radix $(A R)$ in rabbit osteoarthritis (OA) model. Osteoarthr. Cartil. 15, 1086-1092.

Drake, I. M., Mapstone, N. P., Schorah, C. J., White, K. L., Chalmers, D. M., Dixon, M. F. and Axon, A. T. (1998). Reactive oxygen species activity and lipid peroxidation in Helicobacter pylori associated gastritis: relation to gastric mucosal ascorbic acid concentrations and effect of $H$. pylori eradication. Gut 42, 768-771.

Evans, W. C. (2002). Trease and Evans Pharmacognosy, 15th ed. Elsevier Science Ltd., London.

Gerrits, M. M., van Vliet, A. H. M., Kuipers, E. J. and Kusters, J. G. (2006). Helicobacter pylori and antimicrobial resistance: molecular mechanisms and clinical implications. Lancet Infect. Dis. 6, 699-709.

Gui, S. Y., Wei, W., Wang, H., Wu, L., Sun, W. Y., Chen, W. B. and $\mathrm{Wu}, \mathrm{C}$. Y. (2006). Effects and mechanisms of crude astragalosides fraction on liver fibrosis in rats. J. Ethnopharmacol. 103, 154-159.

Gyires, K. (2005). Gastric mucosal protection: from prostaglandins to gene-therapy. Curr. Med. Chem. 12, 203-215.

Hirotani, M., Zhou, Y., Rui, H. and Furuya, T. (1994). Astragalosides from hairy root cultures of Astragalus membranaceus. Phytochemistry 36, 665-670.

Kahraman, A., Erkasap, N., Koken, T., Serteser, M., Aktepe, F. and Erkasap, S. (2003). The antioxidative and antihistaminic properties of quercetin in ethanol-induced gastric lesions. Toxicology 183, 133-142.

Kim, J. J., Kim, J. G. and Kwon, D. H. (2003). Mixed-infection of antibiotic susceptible and resistant Helicobacter pylori isolates in a single patient and underestimation of antimicrobial susceptibility testing. Helicobacter 8, 202-206.

Kim, J. S., Kim, Y. T. and Kim, C. S. (1996). A study on the constituents from the roots of Astragalus membranaceus. Kor. J. Pharmacogn. 27, 336-341.

Kitagawa, H., Takeda, F. and Kohei, H. (1986). A simple method for estimation of gastric mucus and effects of antiulcerogenic agents on the decrease in mucus during water-immersion stress in rats. Arzneimittel Forschung 36, 1240-1244.

La Casa, C., Villegas, I., Alarcón de la Lastra, C., Motilva, V. and Martín Calero, M. J. (2000). Evidence for protective and antioxidant properties of rutin, a natural flavone, against ethanol induced gastric lesions. J. Ethnopharmacol. 71, 4553.

Lee, J. H., Lee, J. Y., Park, J. H., Jung, H. S., Kim, J. S., Kang, S. S., Kim Y. S. and Han Y. M. (2007). Immunoregulatory activity by daucosterol, a $\beta$-sitosterol glycoside, induces protective Th1 immune response against disseminated Candidiasis in mice. Vaccine 25, 3834-3840.

Lee, T. B. (1989). Illustrated Flora of Korea, pp. 491-492.
Hyangmunsa, Seoul.

Lei, H., Wang, B., Li, W. P., Yang,Y., Zhou, A. W. and Chen, M. Z. (2003). Anti-aging effect of astragalosides and its mechanism of action. Acta Pharmacol. Sin. 24, 230-234.

Li, R. J., Qiu, S. D., Chen, H. X., Tian, H. and Wang, H. X (2007). The Immunotherapeutic effects of Astragalus polysaccharide in type 1 diabetic mice. Biol. Pharm. Bull. $\mathbf{3 0}$, 470-476.

Luo, Y., Qin, Z., Hong, Z., Zhang, X., Ding, D., Fu, J. H., Zhang, W. D. and Chen, J. (2004). Astragaloside IV protects against ischemic brain injury in a murine model of transient focal ischemia. Neurosci. Lett. 363, 218-223.

Matysiak-Budnik, T. and Megraud, F. (2006). Helicobacter pylori infection and gastric cancer. Eur. J. Cancer 42, 708-716.

Mizui, T. and Dodeuchi, M. (1983). Effect of polyamines on acidified ethanol-induced gastric lesion in rats. Jpn. J. Pharmacol. 33, 939-945.

Navarrete, A., Arrieta, J., Terrones, L., Abou-Gazar, H. and Calis, I. (2005). Gastroprotective effect of Astragaloside IV: role of prostaglandins, sulfhydryls and nitric oxide. J. Pharm. Pharmacol. 57, 1059-1064.

Nostro, A., Cellini, L., Di Bartolomeo, S., Di Campli, E., Grande, R., Cannatelli, M. A., Marzio, L. and Alonzo, V. (2005). Antibacterial effect of plant extracts against Helicobacter pylori. Phytother. Res. 19, 198-202.

Rajput, Z. I., Hu, S. H., Xiao, C. W. and Arijo, A. G. (2007) Adjuvant effects of saponins on animal immune responses. J. Zhejiang Univ. Sci. B 8, 153-161.

Ríos, J. L. and Waterman, P. G. (1997). A review of the pharmacology and toxicology of Astragalus. Phytother. Res. 11, 411-418.

Seiki, M., Ukei, S., Tanaka, Y. and Soeda, M. (1990). Studies of anti-ulcer effects of a new compound, zinc L-carnosine (Z-103). Nippon Yakurigaku Zasshi 95, 257-269.

Shao, B. M., Xu, W., Dai, H., Tu, P., Li, Z. and Gao, X. M. (2004). A study on the immune receptors for polysaccharides from the roots of Astragalus membranaceus, a Chinese medicinal herb. Biochem. Biophys. Res. Commun. 320, 1103-1111.

Shay, H., Komarov, S. A., Fels, S. S. and Meranze, D. (1945). A simple method for the uniform production of gastric ulceration in the rat. Gastroenterology 4, 43-61.

Tepe, B. and Sokmen, A. (2007). Screening of the antioxidative properties and total phenolic contents of three endemic Tanacetum subspecies from Turkish flora. Bioresour. Technol. 98, 3076-3079.

Tin, M. M. Y., Cho, C. H., Chan, K., James, A. E. and Ko, J. K. S. (2007). Astragalus saponins induce growth inhibition and apoptosis in human colon cancer cells and tumor xenograft. Carcinogenesis 28, 1347-1355.

Tohda, C., Tamura, T., Matsuyama, S. and Komatsu, K. (2006). Promotion of axonal maturation and prevention of memory loss in mice by extracts of Astragalus mongholicus. Br. $\mathrm{J}$. Pharmacol. 149, 532-541.

van de Loosdrecht, A. A., Nennie, E., Ossenkoppele, G. J., Beelen, R. H. and Langenhuijsen, M. M. (1991). Cell mediated cytotoxicity against $U 937$ cells by human monocytes and macrophages in a modified colorimetric MTT assay. A methodological study. J. Immunol. Methods 141, 
15-22.

Zhang, W. D., Chen, H., Zhang, C., Liu, R. H., Li, H. L. and Chen, H. Z. (2006a). Astragaloside IV from Astragalus membranaceus shows cardioprotection during myocardial ischemia in vivo and in vitro. Planta Med. 72, 4-8.

Zhang, W. D., Zhang, C., Liu, R. H., Li, H. L., Zhang, J. T., Mao, C., Moran, S. and Chen, C. L. (2006b). Preclinical pharmacokinetics and tissue distribution of a natural cardioprotective agent astragaloside IV in rats and dogs. Life Sci. 79, 808-815.

Zhang, W. J., Hufnag, P., Binder, B. R. and Wojta, J. (2003). Antiinflammatory activity of astragaloside IV is mediated by inhibition of NF-kappaB activation and adhesion molecule expression. Thromb. Haemost. 90, 904-914. 